\title{
Management of nystagmus in children: a review of the literature and current practice in UK specialist services
}

\author{
J. E. Self $\mathbb{C}^{1,2} \cdot$ M. J. Dunn $\mathbb{1}^{3} \cdot$ J. T. Erichsen ${ }^{3} \cdot$ I. Gottlob ${ }^{4} \cdot$ H. J. Griffiths ${ }^{5} \cdot$ C. Harris ${ }^{6} \cdot$ H. Lee $\mathbb{D}^{1,2} \cdot$ J. Owen ${ }^{6} \cdot$

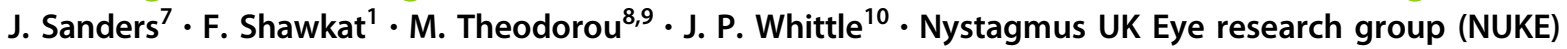

Received: 18 October 2019 / Accepted: 24 November 2019 / Published online: 9 January 2020

(c) The Author(s) 2020. This article is published with open access

\begin{abstract}
Nystagmus is an eye movement disorder characterised by abnormal, involuntary rhythmic oscillations of one or both eyes, initiated by a slow phase. It is not uncommon in the UK and regularly seen in paediatric ophthalmology and adult general/ strabismus clinics. In some cases, it occurs in isolation, and in others, it occurs as part of a multisystem disorder, severe visual impairment or neurological disorder. Similarly, in some cases, visual acuity can be normal and in others can be severely degraded. Furthermore, the impact on vision goes well beyond static acuity alone, is rarely measured and may vary on a minute-to-minute, day-to-day or month-to-month basis. For these reasons, management of children with nystagmus in the UK is varied, and patients report hugely different experiences and investigations. In this review, we hope to shine a light on the current management of children with nystagmus across five specialist centres in the UK in order to present, for the first time, a consensus on investigation and clinical management.
\end{abstract}

\section{Introduction and demographics}

The estimated prevalence of nystagmus in the UK is 24 per 10,000 [1]. It can be broadly grouped into Infantile Nystagmus Syndrome (INS) and acquired nystagmus. The onset of INS is usually within the first 6 months of life (average age $=1.9$ months) [2]. INS can be idiopathic, associated with albinism, retinal diseases such as achromatopsia, congenital stationary night blindness (CSNB) or earlyonset retinal degenerations, low vision in infancy and a variety of other syndromes and developmental diseases (for an exhaustive list, see Leigh and Zee) [3]. The most common forms of INS are idiopathic INS and INS associated with albinism or retinal diseases. The most common form of nonINS nystagmus in childhood is fusional maldevelopment nystagmus syndrome (FMNS, previously Manifest latent nystagmus, MLN).

Members of the Nystagmus UK Eye research group (NUKE) are listed at the end of the paper.

J. E. Self

j.e.self@soton.ac.uk

Extended author information available on the last page of the article.
Children with nystagmus can be severely visually impaired or can have almost normal visual acuity (VA), depending on the underlying disease. However, VA is not a global measure of visual function and nystagmus of any type can associated with significant visual loss [4] beyond that of acuity alone, and accordingly, both nystagmus and albinism are cited as key priorities in the area of childhoodonset disorders, as determined by the Sight Loss and Vision Priority Setting Partnership in 2013.

Despite much research into nystagmus over many years, there are still many unanswered questions about diagnosis, treatment and broad management. Consequently, many clinicians are less comfortable managing children with nystagmus than other conditions and management varies widely. In this review, we seek to clarify the current state-of-play regarding diagnosis, management, treatment options and the use of various investigations in managing this complex group of children.

\section{Basic clinical assessment}

\section{Patient history and examination}

When assessing the infant/child with nystagmus, although INS (with/without associated ocular disorders) is more common, it must be borne in mind that some infants and 
young children will have 'acquired' nystagmus with an underlying neurological cause. Indeed, some older children and/or adults will have previously undiagnosed INS or nystagmus associated with early lack of fusion (FMNS) or, less commonly, nystagmus secondary to severe acquired visual loss. History and clinical examination are both important in tailoring the management pathway to allow appropriate investigations and/or treatment. Since INS is associated with a wide range of underlying disorders, the presence of nystagmus in an infant/child should stimulate a comprehensive search for a cause. Table 1 summarises some of the important questions to be included in a thorough history.

The clinical examination begins as the child enters the room, particularly observing for signs of: photophobia, eye rubbing for retinal stimulation, head postures (variable/ alternating/consistent) and/or head shaking (both often, but not always, after 1 year of age), skin/hair tone particularly in relation to other family members present, as well as signs of associated systemic and neurological features. The examination can then be split into two parts: eye movements and ocular (+/-systemic) examination.

\section{Ocular and systemic examination}

An ocular examination should be performed with the best age-appropriate equipment available, specifically looking for ocular signs commonly associated with nystagmus, which may include:

\section{Cornea}

Size (e.g. microcornea associated with coloboma, or buphthalmic eye associated with glaucoma), epitheliopathy (e.g. associated with $P A X 6$ gene disorders).

\section{Anterior chamber}

Structure (e.g. anterior segment dysgenesis).

Iris

Iris structure (e.g. aniridia, coloboma), iris transillumination (e.g. albinism or some $P A X 6$ related disorders).

\section{Lens}

Cataract, aphakia (congenital/acquired), intraocular lens implant following previous surgery.

\section{Vitreous}

Clarity (e.g. vitreous haemorrhage).

\section{Retina and optic nerve}

Structure, e.g. coloboma, disc anomalies (e.g. papilloedema, hypoplasia, coloboma or small cup seen in albinism), retinal hypo/hyperpigmentation and or pigment, foveal structure (e.g. hypoplasia, atrophy from congenital infection).

Ocular disorders commonly associated with INS are summarized in Table 2.

Where there is any concern that there is an associated systemic or neurological disorder based on either the eye examination or the overall assessment of the child, the infant/child should also be reviewed by a paediatrician or paediatric neurologist.

\section{Red flag signs}

Red flag signs are features in the history and examination which should alert the clinician to acquired pathology that requires further systemic investigations such as neuroimaging.

\section{Red flag signs}

- Later onset nystagmus (in the absence of signs in keeping with an ocular disorder).

- Constant oscillopsia in older children.

- Dysconjugate/gaze evoked/seesaw/convergence-retraction nystagmus.

- Horizontal nystagmus becoming vertical in vertical gaze.

- Vertical or torsional nystagmus (in the absence of retinal pathology (e.g. achromatopsia).

- Any associated neurological signs and/or a systemically unwell child.

\section{Family history}

Taking an accurate family history is an important part of the initial evaluation for all children with nystagmus. If a clear family history of nystagmus is noted, identifying the structure of the pedigree (family tree), in addition to information about the clinical characteristics of those affected, is key. Sometimes it will become apparent that the nystagmus in older relatives seems to be isolated and, in others, is associated with other visual disorders (such as retinal dystrophies or aniridia) or systemic disorders (such as ataxia in the case of spino-cerebellar ataxia syndromes). Asking the degree of visual disability and treatment history for those affected can help to differentiate these groups of disorders. In other cases, the history may include apparently nonocular disorders (such as relatives with strikingly pale skin and hair in contrast to the family context in albinism 
Table 1 History taking in an infant/child presenting with nystagmus.

Question Clinical relevance

Pregnancy, maternal medication/drug use and birth history Maternal drug exposure and prematurity have been associated with nystagmus.

Family history of eye/neurological disease/systemic disease Many eye movement disorders have a hereditary component with different inheritance patterns indicating which genes may be involved.

Pigmentation in skin and hair compared with rest of family Albinism is a common underlying associated disorder, but sometimes without a definite family history.

Specific questions about visual behaviours-e.g. nyctalopia Photophobia and nystagmus are common findings in disorders of cone function or photophobia and albinism. High-frequency low amplitude nystagmus with photophobia is more common in cone dysfunction. Nyctalopia is a common symptom in rod dysfunction.

Open questioning about other visual behaviours

Parents will often report a very detailed description of visual behaviours, which can direct clinical examination such as a child with chin depression and vertically 'wobbly eyes' (commonly seen in downbeat nystagmus), or pushing/rubbing eyes firmly for retinal stimulation in blind babies/children.

Does the child experience oscillopsia?

Lack of oscillopsia in the presence of involuntary eye movements such as nystagmus in an older child suggests early onset. Infrequent episodes of oscillopsia despite a constant nystagmus is also seen in early-onset nystagmus. Constant oscillopsia suggests an acquired disorder.

If oscillopsia is reported, is it when stationary or when moving?

Are there associated speech or swallowing problems?

Are there associated coordination problems?

Is there associated hearing loss or tinnitus?

Is the patient on any medications?

Are there any concerns about any other aspect of the child's development or health besides their eyes?

At what age did the parent/carer notice the nystagmus?
Oscillopsia, which is only present during head movement, implies a vestibular pathology.

Possible brainstem pathology or myasthenia gravis.

Possible cerebellar pathology.

Possible peripheral vestibular pathology.

Many medications can cause abnormalities of eye movement, most commonly anti-epileptic medication.

Eye movement abnormalities form a part of many multisystem syndromes and can be the presenting feature.

INS is typically noticed in the first 4-6 months of life but it's typical onset (when seeking it in at risk patients) is 1.9 months [2]. disorders) or ocular disorders without nystagmus (such as unexplained low vision from a young age in older relatives or night blindness). It is therefore important to ask about any medical disorders in relatives, whether they seem to be related to nystagmus or not, and in all cases to draw a family pedigree in order to narrow the search for potential hereditary causes (and reduce the number of investigations needed in many cases). In many cases, especially where full cooperation is difficult in a young child, examining parents can yield diagnostic information (such as iris transillumination in parents as a clue to albinism as an underlying cause). Figure 1 shows how to draw a pedigree diagram and includes a key to remind clinicians how such diagrams are constructed.

\section{Clinical tip}

When drawing a pedigree diagram, start with the proband (the presenting patient) and work horizontally before vertically where possible. Also include names and dates of birth when available (and according to local data protection policy) and older siblings to the left and younger siblings to the right.

\section{Orthoptic examination}

Orthoptic examination of all children presenting with nystagmus is essential, not only for the comprehensive assessment of visual function and VA throughout the critical period of visual development, but also for investigation of ocular alignment and binocular vision [5]. This is required due to increased prevalence of strabismus in the presence of childhood nystagmus, reported as between 16 and $52 \%[6,7]$. Children with idiopathic INS are less likely to develop strabismus, whereas those with congenital retinal dystrophies or albinism are at intermediate risk, and those with bilateral optic nerve hypoplasia are at particularly high risk [6].

Clinical recommendations for the orthoptic assessment, additional to those discussed in other sections of this paper, are summarised in Table 3; the specific investigation in each case will depend on the age and cooperation of the patient. Additional clinical investigations may be required depending on findings and clinical judgement.

Giving time and relaxing the child as much as possible so that they are comfortable during the orthoptic assessment may give the best performance and improve the responses 
Table 2 Classic presentation of common ophthalmic conditions associated with INS: key points.

Idiopathic INS

Oculo-cutaneous/ocular albinism

PAX6 gene disorders

Achromatopsia
Sometimes family history (typically $\mathrm{X}$-linked). Conjugate, typically horizontal nystagmus, may dampen on convergence, $+/$ - head shake, $+/-$ one/alternating null point, in an otherwise well infant child with normal eyes and systemic examination.

Often family history, typically less pigmentation in hair and skin, hypopigmented iris pigment epithelium (often transillumination) and retinal pigment epithelium, tilted discs and foveal hypoplasia. Evidence of chiasmal misrouting.

Often family history, corneal epitheliopathy, early-onset lens opacity, varying degrees of iris hypoplasia (near normal to aniridic) and foveal hypoplasia. No evidence of chiasmal misrouting.

Often family history, photophobia, reduced/absent colour vision, nystagmus typically 'fine or shimmering' grossly normal macula appearance (may have retinal pigment epithelium (RPE) changes/atrophy).
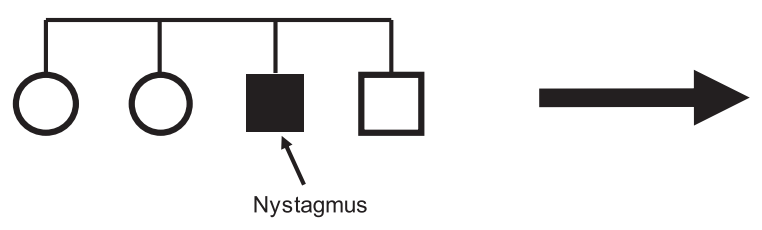
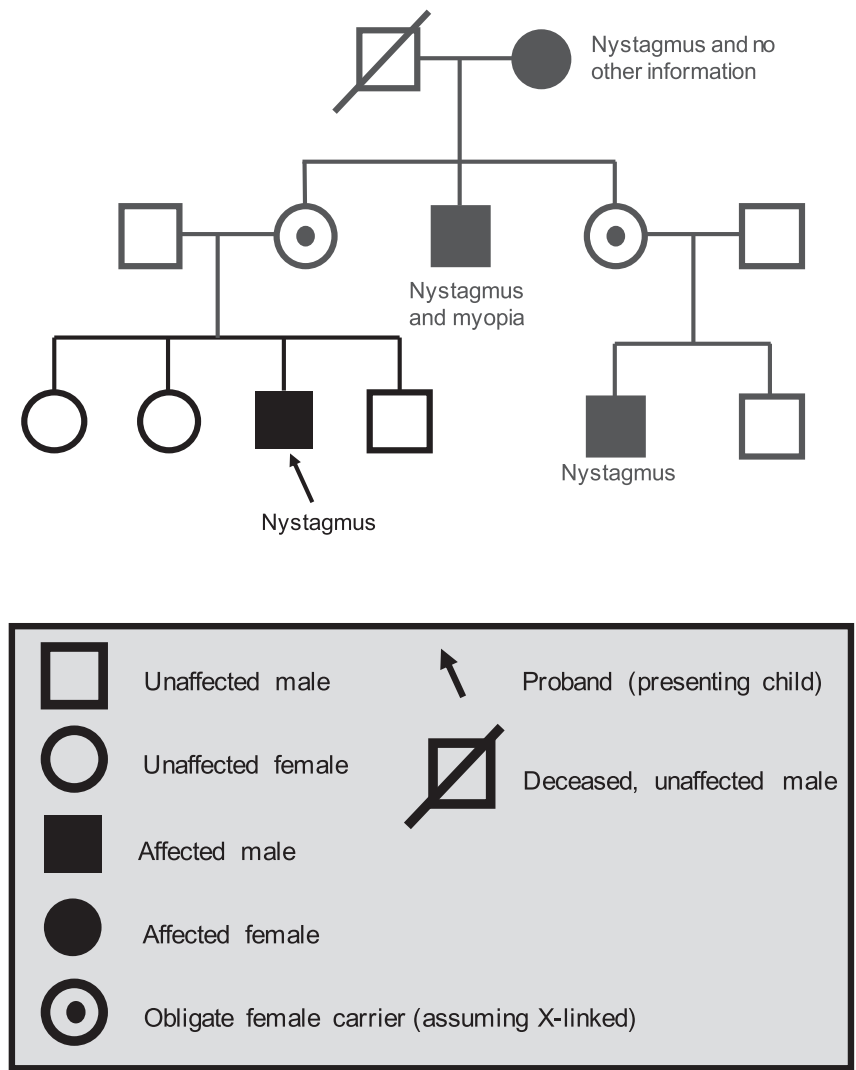

Fig. 1 How to draw a pedigree diagram whilst taking a family history. This pedigree is consistent with X-linked inheritance with variable penetrance in females (typical in FRMD7 gene related INS).

recorded, as both anecdotal reports from patients and experimental studies have reported that the nystagmus intensity increases with increased effort to fixate and decreases when relaxed $[8,9]$.

In the presence of nystagmus, the cover test will be more difficult to perform as small movements to take up fixation can be impossible to distinguish. Observation for asymmetrical corneal reflections may therefore be relied upon. Caution should be taken as a significant association that has been found between a positive angle kappa and clinical signs of albinism in patients with INS [10].

\section{Clinical tip}

The involuntary head nodding often seen in INS can be distinguished from rhythmic head movement due to a more sinister cause; if the child can voluntarily stop the head movement when asked, it is caused by the nystagmus.

\section{Nystagmus examination}

A simple, methodical clinical assessment of a child's nystagmus can provide key information in order to direct further investigations. It can sometimes identify the type of 
Table 3 Orthoptic assessment in children with nystagmus.

\begin{tabular}{|c|c|}
\hline Clinical test & Description \\
\hline Head posture & $\begin{array}{l}\text { - Presence and degree of any anomalous head posture (AHP) should be } \\
\text { recorded-including a description for both near and distance fixation, with } \\
\text { and ideally without any refractive correction. } \\
\text { - Any change with visual demand should be noted. } \\
\text { - Presence or absence of any involuntary head nodding should be recorded with } \\
\text { activity in which this occurs. }\end{array}$ \\
\hline VA & $\begin{array}{l}\text { - With refractive correction-both eyes open and monocularly. } \\
\text { - A note taken as to whether measured with or without head posture. } \\
\text { - Near using preferred reading distance and distance. } \\
\text { - Record method of occlusion, e.g. opaque occluder/high plus lens. }\end{array}$ \\
\hline Cover test & $\begin{array}{l}\text { - With and without refractive correction. } \\
\text { - With and without AHP. } \\
\text { - Near and distance fixation. } \\
\text { - Note presence or absence of nystagmus, any change in amplitude and/or } \\
\text { direction of nystagmus on covering one eye. }\end{array}$ \\
\hline Binocular single vision & $\begin{array}{l}\text { - With refractive correction and any AHP. } \\
\text { - Sensory, motor fusion for near and distance fixation. } \\
\text { - Presence or absence of stereopsis-stereoacuity when possible. } \\
\text { - Note AHP adopted to achieve binocular responses. }\end{array}$ \\
\hline Ocular movements & $\begin{array}{l}\text { - Testing of ductions and versions in nine positions of gaze for near fixation, } \\
\text { with description of nystagmus in primary and secondary positions. } \\
\text { - VOR (vertical and horizontal)-presence/absence. } \\
\text { - Optokinetic nystagmus (OKN)_-presence/absence/abnormal (expected or } \\
\text { inverted response). } \\
\text { - Smooth pursuit-horizontal and vertical. } \\
\text { - (For detail of methods of testing, see Osborne et al. [5]). }\end{array}$ \\
\hline Convergence & $\begin{array}{l}\text { - With refractive correction with AHP_noting ability to convergence and } \\
\text { change in amplitude and/or frequency of nystagmus. }\end{array}$ \\
\hline Measurement of deviation & $\begin{array}{l}\text { - If possible, using alternating prism cover test-with refractive correction, } \\
\text { with and without AHP. } \\
\text { - Near and at distance-primary position, secondary positions if indicated to } \\
\text { document change from primary position or to confirm concomitance. } \\
\text { - Individual reading position if different from above. }\end{array}$ \\
\hline
\end{tabular}

nystagmus, but it can also rule out, or at least reduce the likelihood of, some nystagmus aetiologies. Even if the nystagmus type cannot be identified, it is important to document its features. There are different diagrammatic schemes for describing the nystagmus in the medical notes, but consistency is important. Using words, whilst verbose, does avoid confusion.

The initial and crucial task is to look for nystagmus in all gaze directions, not just primary position (usually the nine cardinal points). There may be nystagmus in far eccentric gaze, which can be easily overlooked in an uncooperative child, so perseverance is required. The axis of oscillation, whether it is horizontal, vertical, torsional, circumrotatory (i.e. circular or elliptical) or a mixture, should be noted at each cardinal point. Does the nystagmus appear similar in each eye (i.e. conjugate), or is there an asymmetry? If the nystagmus appears jerky, document the direction of the fast phase, otherwise note that it appears pendular. Note the frequency (how fast) and amplitude (how big).

It is also important to examine the nystagmus during monocular viewing to look for FMNS, which is relatively common either as the sole nystagmus or in conjunction with other types of nystagmus (usually INS). In sole FMNS, the nystagmus is conjugate, horizontal and in primary position, beats in the direction of the viewing eye. That is, the nystagmus reverses with alternate occlusion. The nystagmus also intensifies with increased abduction of the viewing eye and dampens (sometimes completely) in full adduction. Thus, FMNS is usually best identified by alternating occlusion with the eyes in far lateral gaze, as this will bring out the biggest change in intensity. Patching may sometimes be preferable to an occluder in the young uncooperative patient.

Typically, INS is horizontal and remains so in elevation and depression. The nystagmus often has a null region (a direction of gaze in which the nystagmus dampens) and increases in intensity, becoming jerkier farther from the null.

Gaze-evoked nystagmus is the most common acquired nystagmus. It is usually caused by cerebellar lesions/malformations or drug toxicities (esp. anticonvulsants). The nystagmus is evoked on lateral gaze but absent in primary position. It beats in the direction of gaze, similar to FMNS but is unaffected by monocular occlusion. There may (or 
may not) be downbeat nystagmus in lateral gaze or depression. In elevation, there may (or may not) be unsteady gaze or upbeat nystagmus. Horizontal smooth pursuit is almost always quite saccadic, which is one way to differentiate it from end point nystagmus.

If the nystagmus is downbeat, upbeat or asymmetric, then a neurological cause should be considered, although INS cannot be excluded. Periodic Alternating Nystagmus (PAN) describes a horizontal jerk nystagmus that reverses direction every few minutes. PAN can occur as an acquired neurological nystagmus or as an aspect of INS (often raising suspicion of albinism as the underlying aetiology). To test for PAN, the nystagmus should be examined for a reversal in direction for at least $5 \mathrm{~min}$. It is important to keep the gaze in primary position, otherwise a spurious reversal could occur due to a gaze-evoked null shift. Such prolonged observations can be difficult for young or non-compliant patients. If the nystagmus beat direction (or anomalous head postures (AHP)) is different than indicated in previous notes or reports by carers, then PAN should be suspected. When associated with INS, PAN has no sinister implications but may be a contraindication for standard AHP surgery as it implies spontaneous null shifting.

\section{Clinical tip}

For a more detailed, practical description of how to examine nystagmus and other supranuclear eye movements in children (and interpret findings), see [5].

\section{Specialised clinical assessment}

\section{Optical coherence tomography (OCT) in INS}

OCT imaging has been established as a tool that can streamline diagnosis of the aetiology of INS [11-31]. For infants and young children who cannot cooperate with standard table-top OCTs, a hand-held spectral-domain OCT imaging device can be used, which has been shown to be reliable in the presence of nystagmus [32]. By identifying the presence or absence of typical or atypical foveal hypoplasia (continuation of the normally absent inner retinal layers (IRLs) across the fovea) and the presence of other abnormal morphological features, it is possible to divide INS into four diagnostic categories: (1) typical foveal hypoplasia; (2) atypical foveal hypoplasia; (3) abnormal foveal morphology; and (4) normal foveal morphology (Fig. 2) [31]. In this way, conditions such as albinism and PAX6 mutations, which are usually associated with typical foveal hypoplasia (Fig. 3a), can be distinguished from other conditions such as achromatopsia, which is characterised by atypical foveal hypoplasia (Fig. 3b), or retinal dystrophies, which are typically associated with abnormal foveal

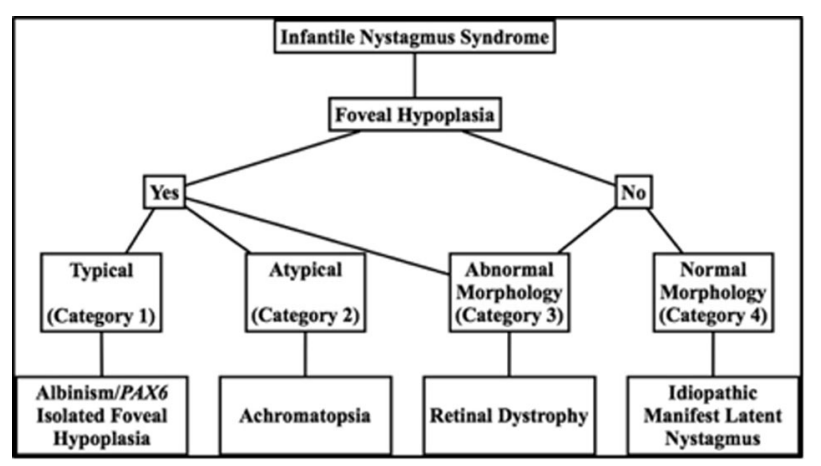

Fig. 2 Diagnostic use of OCT in INS. An algorithm adapted from 'potential of hand-held optical coherence tomography to determine cause of INS in children by using foveal morphology' [31].

morphology (Fig. 3d). Furthermore, the severity of foveal hypoplasia can be graded (Fig. 4), and this can potentially be used as a visual prognostic indicator [33].

\section{Clinical tip}

There are frequently movement artefacts in macular OCTs from patients with INS. When attempting to diagnose foveal hypoplasia, obtain a macular volume scan, ensuring that (1) the optic nerve is visible as a landmark and (2) there is a minimum of five uninterrupted $B$ scans (i.e. without refixations or blinks on either side of the central foveal B scan).

\section{Eye movement recordings (EMRs) in INS}

EMR, if available, provides a means for objectively visualising the details of oculomotor phenomena that are not visible to the naked eye or occur transiently. EMR can also provide a permanent quantitative record for longitudinal comparisons to monitor disease progression or remission. EMR is particularly valuable for patients with oscillatory eye movements as it can reveal the underlying nystagmus waveform that distinguishes various types of nystagmus and saccadic oscillations. EMR recording can also detect abnormal smooth pursuit, saccades, OKN, and vestibular responses depending on the type of equipment at hand [34].

Modern eye trackers are mostly video based and provide non-intrusive accurate recordings with high resolution for horizontal and vertical eye movements. Hence, they are capable of providing objective evidence for the presence and type of nystagmus, but also for the absence of nystagmus. Note that the majority of EMR systems do not record torsional eye movements; for this, highly specialised equipment is needed.

In a busy clinical setting, it is usually not possible to perform a standardised battery of EMRs with each patient. Instead, and where available, EMRs can help address 


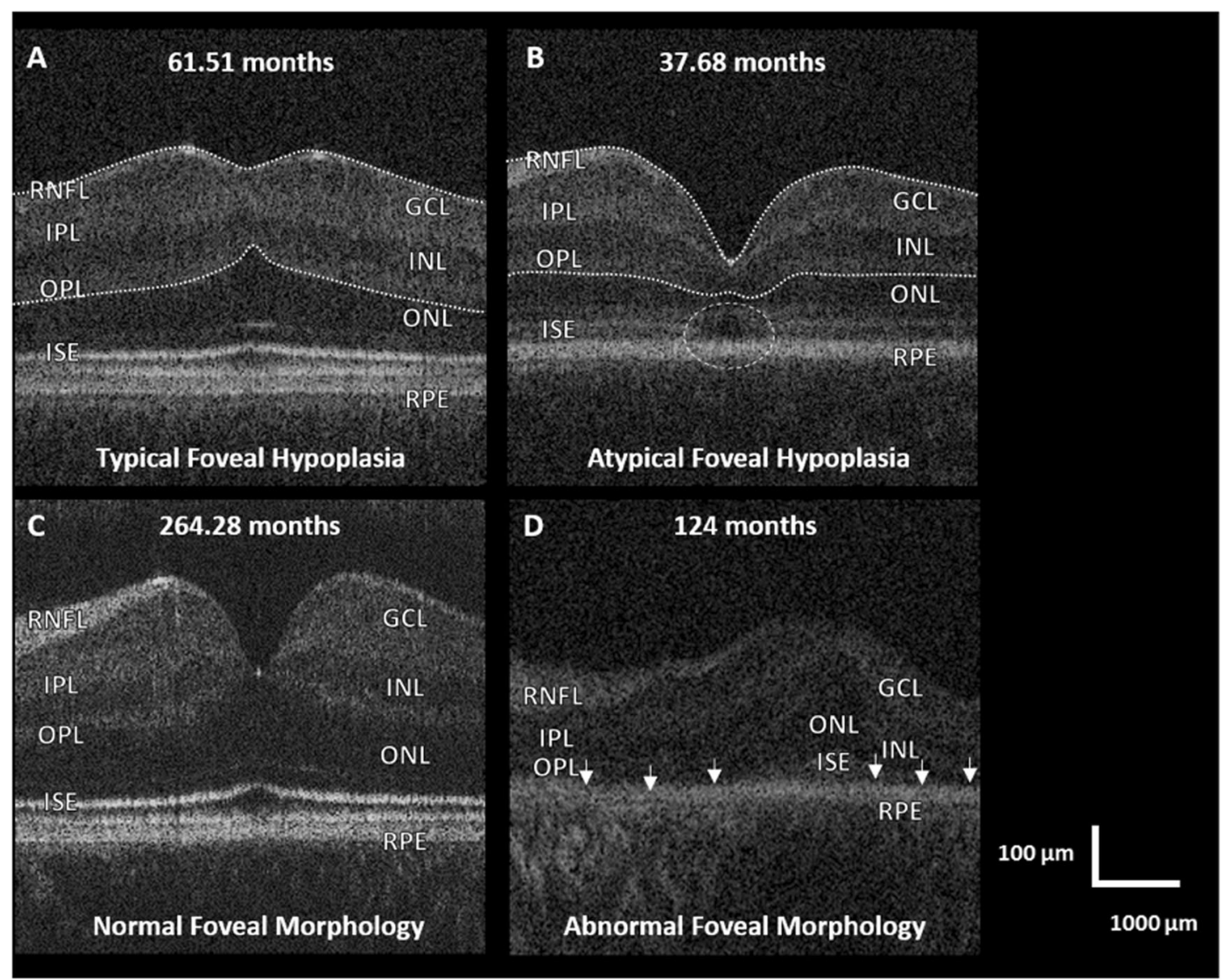

Fig. 3 Foveal tomograms obtained from children, which demonstrate some of the diagnostic features seen in INS on OCT imaging. (Adapted from [16]). a Typical foveal hypoplasia, where there is continuation of the normally absent IRLs (outlined in white) in a case of albinism. b Atypical foveal hypoplasia in achromatopsia where, in addition to foveal hypoplasia (IRLs outlined in white), there is Inner

outstanding clinical questions where other examination is equivocal. For example an accelerating slow phase is virtually pathognomonic of INS, regardless of age and any underlying sensory defect [35].

Eye oscillations can occur intermittently, either as a postsaccadic phenomenon, or as a burst of oscillations with no apparent predisposing factor. The differential diagnosis for these phenomena is wide including paroxysmal/epileptic nystagmus, organic ocular flutter, opsoclonus, psychogenic flutter, square-wave jerks and saccadic dysmetria. Their transient nature can lead to difficulty in their identification, but are nearly always resolved by EMR. EMR can also provide useful information about other eye movement abnormalities, whether or not nystagmus is also present. For example, saccadic disorders are notoriously difficult to visualise clinically and various abnormalities such as disorders of speed, accuracy and triggering ability can be missed. Furthermore, $\sim 1$ in 20 people can voluntarily induce a high frequency, low amplitude ocular oscillation segment ellipsoid band (ISE) disruption and a hypo-reflective zone (white circle). c Normal foveal morphology. d Retinal dystrophy consisting of: absent rod photoreceptors and ISE (small white arrows), ONL thinning and abnormal lamination of the inner retinal layers seen in a case of microcephaly lymphoedema and chorioretinal dysplasia.

[36] called psychogenic flutter, sometimes incorrectly referred to as psychogenic/voluntary nystagmus. This phenomenon is not a form of nystagmus, as it consists of backto-back saccades with no slow phase. It is not an uncommon reason for presentation to the paediatric eye clinic and must be differentiated from nystagmus or opsoclonus/ocular flutter that requires more extensive investigations.

If available, EMR can also be useful for surgical planning and monitoring results, e.g. through documentation of the presence or absence of PAN and/or the null zone position and pre and post-surgery waveforms. See Fig. 5 for some clinical examples illustrating when EMR can be particularly useful in dictating subsequent investigation and management for children referred with nystagmus.

\section{Electrodiagnostics}

Visual electrodiagnostics are tests that assess the function of the afferent visual pathway from retina to cortex. Retinal 
Fig. 4 Grading foveal hypoplasia. An algorithm for grading foveal hypoplasia on the basis of OCT findings. Adapted from [33].

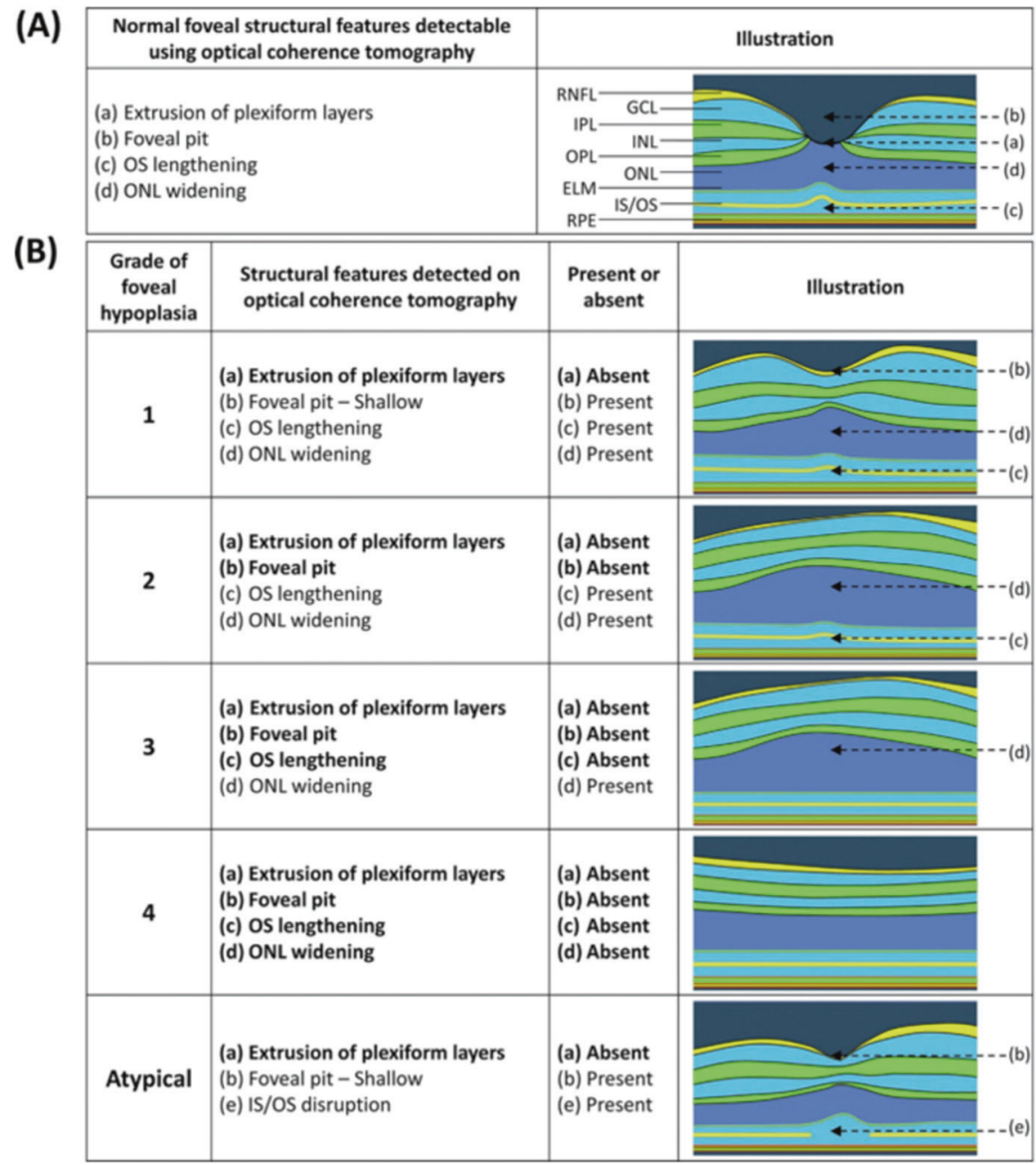

function is assessed using the electroretinogram (ERG) and the post retinal pathway using visual evoked potentials (VEP). Paediatric ERGs and VEPs are non-invasive, objective tests that do not require any anaesthesia, sedation or mydriasis. The tests are relatively quick to perform (30-40 min) with immediate access to results and are performed according to a modified, combined paediatric protocol [37]. Adults with nystagmus should be investigated using the standards and recommendations of the International Society for Clinical Electrophysiology of Vision [38].

A common cause for nystagmus in children is retinal dystrophy, and in many cases, a fleeting posterior segment examination is normal. These patients need ERGs and VEPs to assess retinal integrity and isolate cone and rod function: severe retinal dystrophy, such as Leber's amaurosis, results in all ERGs being attenuated, whereas in achromatopsia, cone-mediated ERGs are attenuated but rod ERGs are normal. Alteration in the ERG waveform that results in a negative configuration (better preserved ERG 'a' wave than 'b' wave) is commonly seen in an X-linked CSNB and Xlinked retinoschisis. Pigmentary retinopathies can also be associated with a number of systemic and neurometabolic conditions that may be present with nystagmus: ERGs are degraded with rod responses often more severely affected initially with later involvement of the cones.

The concurrent recording of pattern VEPs determines the extent of macula involvement and provides an estimate of the level of vision. A patient could have extinguished flash ERGs but preserved pattern VEPs, indicating retinal dysfunction primarily involving the extra-macular areas, whereas pattern VEPs are degraded in patients with cone dysfunction. VEPs should be recorded to a range of different size patterns: black and white checkerboard pattern that is alternating (pattern reversal) or appearing and disappearing (onset/offset VEPs). Patients with nystagmus have degraded pattern VEPs corresponding to their decreased vision. However, if ERGs are normal but VEPs are degraded to all pattern sizes, then a postretinal problem needs to be excluded. Neurological conditions such as optic nerve hypoplasia, glioma, craniopharyngioma and achiasmia may present with nystagmus, and the VEPs in these patients can be abnormal not only in waveform, but also in distribution across the occiput. Midline and lateral scalp 
A

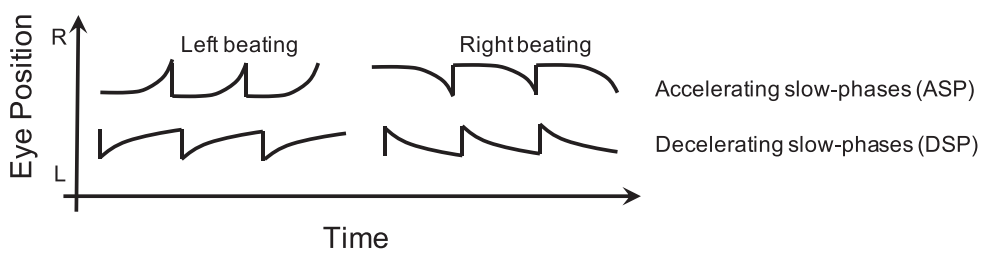

$\mathrm{B}$

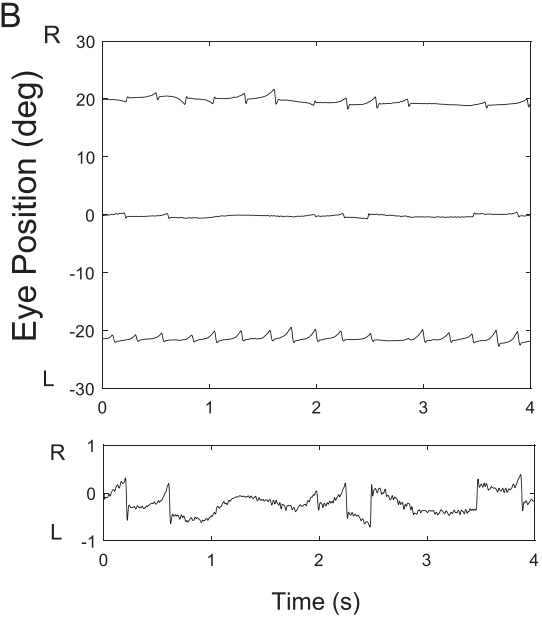

Fig. 5 Examples of the use of eye tracking in clinical cases. a Schematic of idealised horizontal jerk nystagmus waveforms showing (top row) accelerating slow phases (ASP's) that are almost pathognomonic for infantile nystagmus (INS), and bottom row decelerating slow phases (DSP's), which are typically seen in FMNS and acquired gaze-evoked nystagmus. b Example from a 6-year-old boy referred with apparent recent onset of gaze-evoked nystagmus. Urgent brain MRI was normal and there were no other neurological signs. EOM recording revealed a conjugate horizontal jerk nystagmus in lateral gaze with clear ASPs (top panel). In primary position, nystagmus was not evident clinically, but recordings showed a very fine nystagmus with frequent ASPs (bottom panel). Conclusion was INS
C

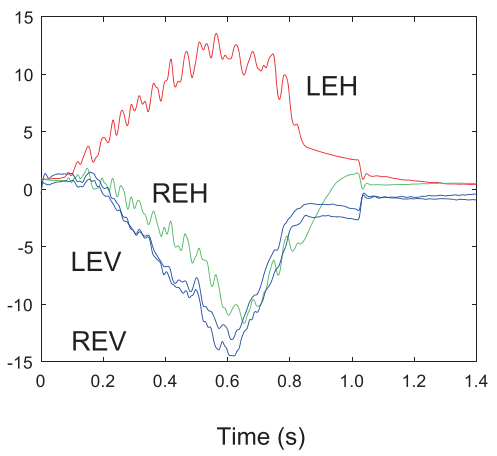

since infancy that had been undetected due to broad null around primary position, and MRI was had not been necessary. c A 15 -year-old female presented with spasms of oscillopsia and blurred vision that were correlated with clinically visible flutter-like episodes. EOM recording showed sporadic bursts of back-to-back saccadic oscillations that were predominantly horizontal. Episodes were not post-saccadic oscillations, as typically seen in ocular flutter, but were associated with spontaneous convergence and conjugate depression. Upon questioning, patient demonstrated ability to generate voluntary nystagmus with convergence at will. Precautionary brain MRI and chest X-ray were normal. Conclusion was 'involuntary' voluntary nystagmus or 'eye movement tics' [4]. electrodes are used to enable the recording of the contributions of each occipital hemisphere to the VEP. If the occipital distribution shows an asymmetry that is similar for the two eyes, (uncrossed asymmetry) then hemispheric dysfunction is indicated; if the asymmetry for stimulation of one eye reverses when the other eye is stimulated (crossed asymmetry), then a chiasmal anomaly is indicated.

Albinism and its associated excessive decussation of chiasmal fibres may lead to a crossed VEP asymmetry. The asymmetry is more conspicuous on monocular flash VEP testing in infants and becomes less conspicuous in older children and adults, where it is better seen using pattern reversal and onset stimulation. Previously, a crossed asymmetry was believed to be a prerequisite for the diagnosis of albinism. However, it is common to see children with genetically confirmed albinism but no crossed asymmetry. It seems that, for children with more severe albinism phenotypes (typical foveal hypoplasia, iris transillumination, skin and hair signs), crossed asymmetry is common and clear (and arguably unnecessary for the clinical diagnosis anyway), however for those with hypomorphic (less obvious) albinism phenotypes such as OCA1b, crossing is far less reliable and as such its role in albinism diagnosis is often limited.

Young infants with INS can present with large amplitude pendular nystagmus that results in the infant appearing to have roving eyes. Electrodiagnostics are essential to establish whether there is a visual pathway problem as well as to gain an insight into the level of vision. Vertical and torsional nystagmus, as well as nystagmus that is asymmetric when comparing the two eyes, is strongly associated with neurological disease. However, such atypical nystagmus is seen in retinal dystrophies, CSNB, albinism and idiopathic INS [39], indicating that although neuroimaging can be necessary in such cases, non-invasive, electrodiagnostic studies remain important and should be carried out in all such children.

It is important to note that the role of electrodiagnostics in children with nystagmus goes beyond that of initial diagnosis alone (see Fig. 6). 


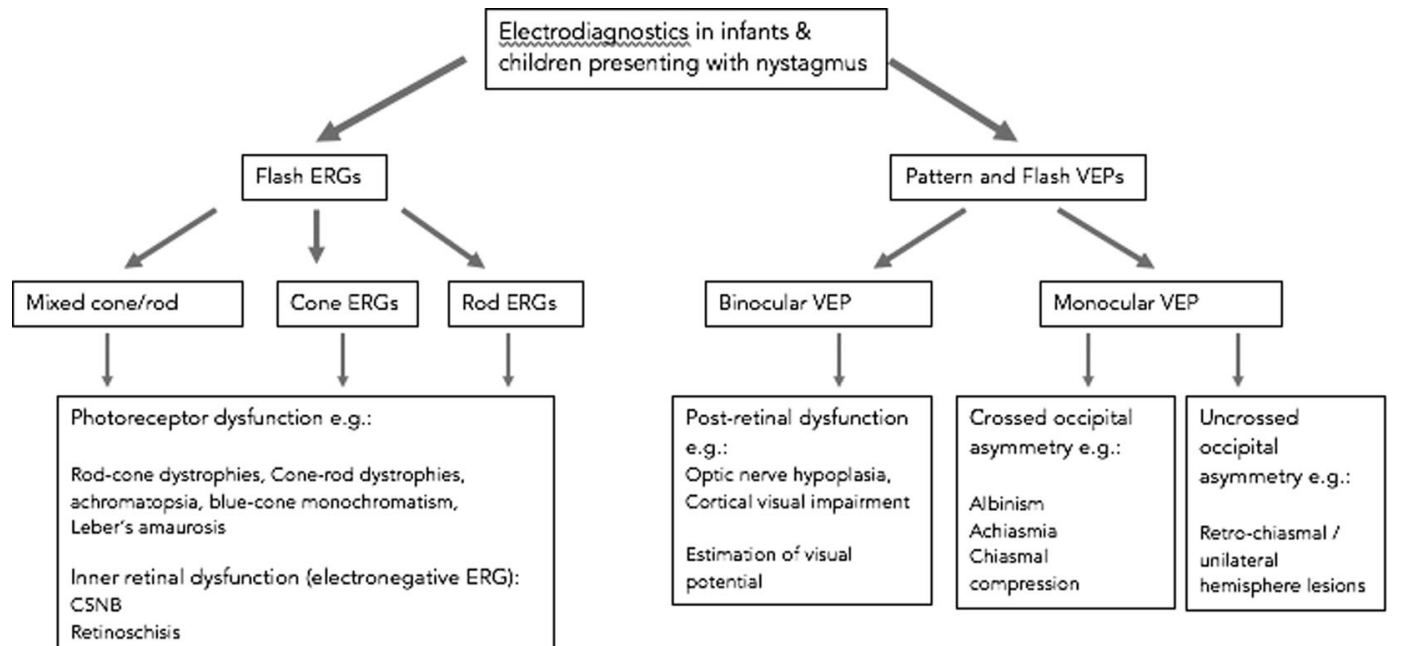

Fig. 6 The use of visual electrodiagnostics in diagnosing nystagmus. A schema summarising the role of paediatric visual electrodiagnostic for aiding diagnosis in infants and children presenting with nystagmus. It is imporant to note that visual electrodiagnostic testing has other roles besides diagnosis such as evaluating potential for vision which is discussed elsewhere.

\section{Diagnostic workflow}

When seeking a diagnosis for children with nystagmus, it is important to recognise the limitations and inconsistent access to clinical equipment. For example, a 4-month-old infant who has nystagmus, but for whom no other clinical information is available, may have profound visual loss, a significant neurological disorder, albinism or many other disorders. The degree of phenotyping (clinical assessments/descriptions) dictates the ability to narrow the search for these groups of disorders. Some clinical diagnostic tools are freely available (such as direct anterior and posterior segment examination) and some are scarcer (such as hand-held OCT or electrodiagnostics). Most diagnostic workflows used in practice have the aim of streamlining the diagnostic process for as many children as possible by relying on the most freely available diagnostic tests and seeking the most urgent diagnoses as a priority. However, the inconsistency in approach has led to significant variations in clinical practice, sometimes including unnecessary invasive tests (such as Magnetic Resonance (MR) neuroimaging often requiring general anaesthesia) and a lack of resulting diagnosis for many infants/children. In practice, most diagnostic workflows seek to identify which of seven common patient groups children referred with nystagmus fall into as they broadly guide subsequent management or further investigation (see Table 4).

As discussed in Table 4, most patients following detailed clinical workup will fall into one of seven patient categories. However, the process of prioritising the investigations and the order in which they are completed varies significantly, partly due to the availability of clinical resources. In Fig. 7, we propose a diagnostic workflow that forms the basis of our clinical practice across a number of specialist paediatric nystagmus services in the UK. It is important to note that this workflow focusses on the initial route to diagnosis only, and in many cases, additional tests will be required to support clinical management, for example VEP testing in order to quantify visual pathway lesions and visual prognosis in most cases.

\section{Genetic testing}

As detailed above, genetic testing forms a part of diagnosis for many children with nystagmus. Indeed, the role of genetic testing has changed significantly with the recent advent of multi-gene testing panels for clinical use. Currently, a variety of gene panels are relevant to children with nystagmus [40, 41]. Clinical phenotyping is a necessary prerequisite in order to select the appropriate panel (e.g. a retinal dystrophy identified clinically might advocate a retinal, rather than albinism, gene panel). NHS England is currently in a process of standardising these panels, and the genes that comprise them in addition to widening access to testing and centralising funding. Future approaches might differ from the current model, such as implementing much broader gene panel testing (such as those including all genes known to cause any eye disease) and using these as the first steps towards diagnosis with subsequent phenotyping employed to prove or disprove putative genetic diagnoses. These differing approaches are currently the topic of much debate, and clinicians will increasingly be required to understand the limitations of genetic testing along with its changing role in diagnostics, in many cases through closer collaboration with clinical genetics colleagues. Future directions are likely to be dictated by the cost and speed of genetic testing but will always require detailed clinical 
Table 4 Seven of the most common patient cohorts into which most children presenting with nystagmus fall.

Patient cohort Description

Idiopathic infantile nystagmus syndrome (IINS)

Seen in patients with no apparent cause for nystagmus either systemically or after detailed ocular examination. Typical clinical features include onset between 4 and 6 months of age, horizontal nystagmus, staying horizontal in vertical gaze, beating in the direction of gaze, dampening on convergence and associated with null zones and head postures. Typically, further investigation would include electrodiagnostics, OCT and genetic testing but not MRI brain imaging.

Nystagmus due to inherited retinal dystrophy

Clinical features may include photophobia, nyctalopia and very low VA. The nystagmus can be multiplanar and often high intensity (fast and small amplitude). Typically, further investigation would include electrodiagnostics, OCT and either retinal gene panel testing or additional retinal phenotyping but not MRI brain imaging.

Nystagmus with abnormal ocular findings (not retinal dystrophy)

Often subtle signs suggesting a group of underlying disorders such as iris transillumination or foveal hypoplasia suggesting hypomorphic forms of PAX6 gene disease, mutations in SLC $38 A 8$ or albinism spectrum disorders. Further investigation would typically include additional ocular or non-ocular phenotyping, VEP and OCT or bespoke genetic testing and not MRI brain imaging.

Fusion maldevelopment nystagmus syndrome (FMNS, previously MLN)

Caused by early loss of binocularity and seen very commonly in strabismus, congenital cataract and any cause of early visual loss. Typical clinical features include horizontal nystagmus that beats in the direction of the viewing eye with monocular occlusion and that dampens in adduction of the viewing eye. Typically, no further investigation is required.

Acquired nystagmus or those with significant As these cases are rarely caused by true congenital genetic disorders, most warrant systemic, investigation in the first instance. Clinical features may include an older patient (or child older than 6 months) with recent onset nystagmus, not beating in the direction of gaze and associated with oscillopsia. Typically, MR neuroimaging would form an early part in further investigation in addition to electrodiagnostics.

Nystagmus in a patient with very poor vision from As any cause of poor vision in infants can cause a stimulus deprivation nystagmus (such as infancy (not retinal dystrophy) congenital cataract or optic nerve hypoplasia). Clinical features may include obvious clinical signs and very poor vision with nystagmus of varying forms. Further investigation would be directed by the findings and typically include electrodiagnostics to assess postretinal and chiasmal integrity as well as levels of vision.

Non-nystagmus eye movement disorders

Such as abnormal square-wave jerks, psychogenic flutter, opsoclonus or ocular flutter. These disorders can be misdiagnosed as nystagmus but have different aetiologies and investigation pathways according to findings.

These cohorts broadly dictate the next line of investigation of management, and clinical investigation workflows are designed in order to arrive at one of these broad diagnostic categories for most patients

assessment in order to confirm or refute putative genetic diagnosis (which can be numerous when many genes are tested at once) [42] and direct future clinical care.

\section{Treatments and ongoing medical care}

\section{Refractive treatment}

Refractive correction is a priority when managing children with nystagmus. Contact lenses may be superior to glasses in improving visual function, due to a combination of optimal optical correction in a constantly moving eye, as well as an additional proprioceptive effect (see Table 5). Contact lenses can be helpful for patients with a significant refractive error and a significant AHP (as such patients otherwise tend to be limited by the frame of their glasses). Both rigid gas permeable (RGP) and soft contact lenses (SCL) are able to correct very large refractive errors and significant astigmatism (up to 15.00 DC with soft), although traditionally RGPs have been used in INS.

Prisms are an alternative form of refractive correction. By moving images, prisms can be used to exploit a convergence null, or null point/zone with a small associated compensatory head posture, either as short term preoperative assessment or (far less commonly in the UK) as longer term management.

To date, there are only two published randomised trials looking at refractive correction in INS, and a further 12 case reports/series (summarised in Table 5): eight looking at contact lens wear, three at prism therapy and one port-hole treatment.

Jayaramachandran et al. [43] reported a randomised, controlled cross-over trial with an intention-to-treat design comparing spectacles, SCL and RGP wear. There was a total of 24 participants (12 idiopathic, 12 with albinism). There were no significant differences in nystagmus intensity or any nystagmus parameter with either contact lens wear compared with the 


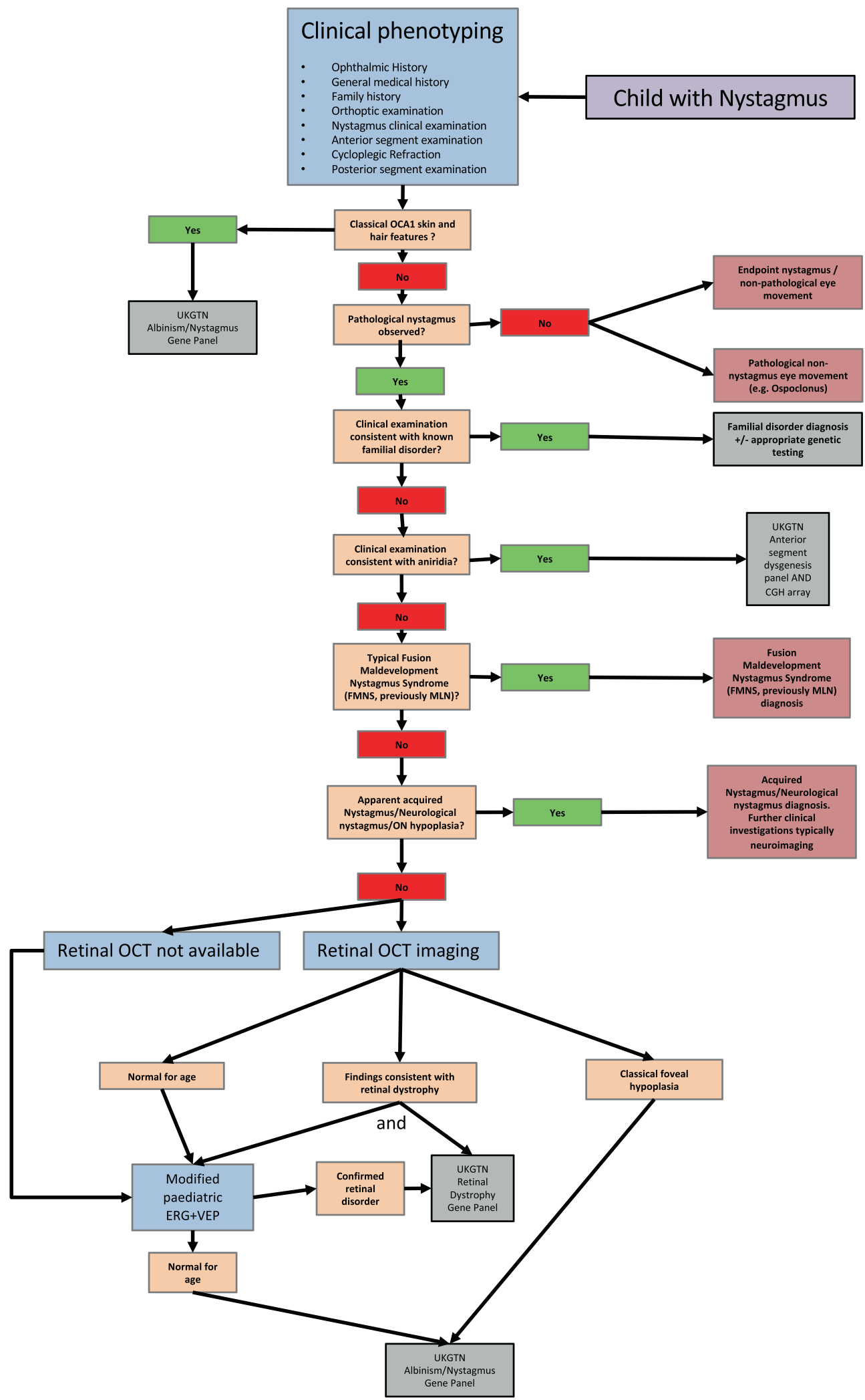

Fig. 7 A diagnostic workflow that forms the basis of our clinical practice across a number of specialist paediatric nystagmus services in the UK. It is important to note that most cases will require additional evaluation for visual prognosis and/or monitoring (e.g. electrodiagnostics in the case with optic nerve hypoplasia) and this pathway is meant as a guide to seeking an initial diagnosis only. 


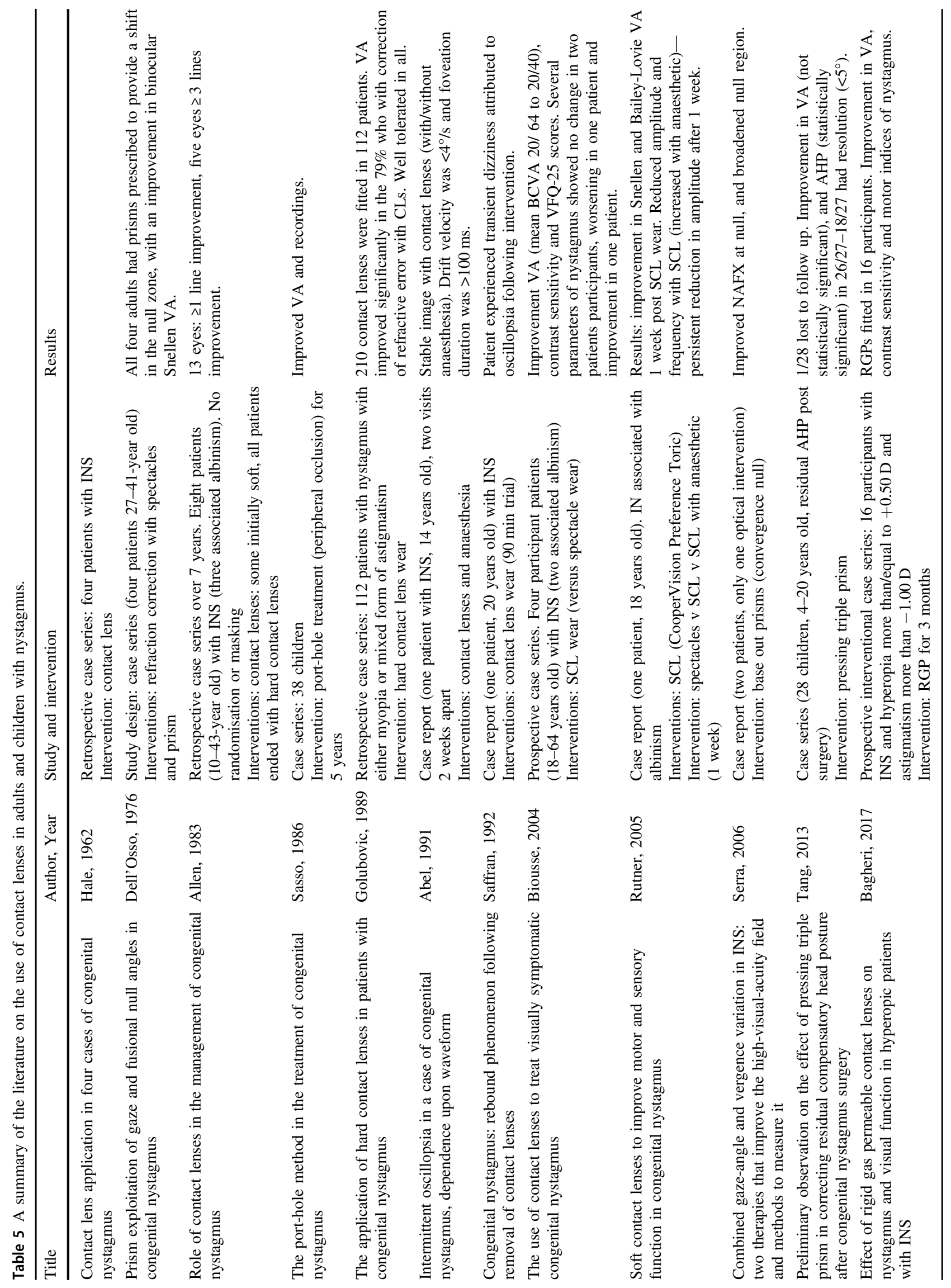


baseline of spectacle wear. In fact, there was a worsening of near vision in both groups, despite a reduction in intensity.

Theodorou et al. [44] reported a pilot randomised control trial comparing fully corrective SCL with plano SCL in a group of 38 adult idiopaths. Despite the small effect size, there was an improvement in best corrected VA (BCVA) in both groups along with an improvement in some of the waveform parameters, in keeping with published data. However, due to the contrasting results, a larger randomised control trial is required to confirm/dispute the use of contact lenses as a safe evidence-based option for treatment in people of all ages, particularly in young children with greater plasticity in the visual cortex.

In the authors' experience, some children and young adults report good outcomes from contact lenses, particularly where high refractive errors are present and, as such, contact lenses should be considered, particularly in older children, but the possible benefit should be weighed against risks of CL related complications such as infection.

\section{Medical treatment}

Baclofen, gabapentin, cannabis, memantine, aminopyridines and several other drugs have been used in acquired nystagmus [45-47]. Baclofen has been shown to be useful in infantile PAN. Gabapentin (up to $2400 \mathrm{mg}$ in divided doses) and memantine (up to $40 \mathrm{mg}$ in divided doses) have been found to be useful in reducing nystagmus intensity in INS and in some patients to increase VA [48]. Both are usually well tolerated if the dose is increased slowly. Pregabalin has also been used in some cases, and brinzolamide eye drops are gaining popularity worldwide but with limited supportive evidence. Most systemic drugs used to treat nystagmus, whether acquired or infantile, have significant side-effect profiles, and it is not clear which patients respond best, and at what age, and clearly larger clinical trials are needed before most are included in routine clinical practice. It is also worth noting that the aim of treatment varies widely between patients, for example those with INS and no oscillopsia and an adult with acute onset nystagmus and disabling oscillopsia. Most medical treatments have been used in patients over 16 years of age.

\section{Surgical treatment}

Current evidence suggests that the Kestenbaum-Anderson procedure is an effective treatment to correct AHP occurring secondary to an eccentric null zone in INS. This is achieved by creating a gaze palsy in the preferred direction of gaze [49-51]. The classical procedure was modified by Parks [52] to the well-known ' $5,6,7,8$ ' procedure. Subsequently, it was recommended that the classical surgical amounts be augmented by $40 \%$ for AHPs up to $30^{\circ}$ and $60 \%$ when an AHP exceeds $45^{\circ}$ [53-58], or that a greater amount of symmetric surgery be performed [59-61]. With these modifications, $72-100 \%$ of patients achieve an AHP of $15^{\circ}$ or less postoperatively [53, 56, 58, 62-65]. Smaller surgical amounts are required to correct a vertical AHP [66]. We recommend the simpler approach of performing large amounts of symmetric surgery, where possible (Table 6). Up to $43 \%$ of patients achieve increases in BCVA and up to a $60 \%$ reduction in recorded recognition times [58, 62, 67, 68] in some studies, but debate still exists particularly regarding improvements in VA. Up to $40 \%$ of patients may require additional surgery after a mean interval of 6 years for under-corrections [69].

Preoperatively, an AHP should be evaluated by testing both with and without glasses at both distance and near, monocular and binocularly, noting the direction and degree of AHP adopted when maximal visual effort is exerted. Of particular importance is the identification of PAN, FMNS or co-existent strabismus, in which the recommended surgical approach needs to be altered. A standardised method for the objective measurement of the size of the AHP remains to be established, with many surgeons relying on photos and subjective estimates [70]. Objective methods that can be used for measuring AHP, including using a cervical range of motion device [71], orthopaedic goniometer [72], torticollometer, Harms' wall $[73,74]$ and other devices. More recently developed smartphone applications may also have a role in the evaluation of AHP [75] but are not in routine use currently.

AHP surgery during the pre-school years to optimise visual function and alleviate the cosmetic defect prior to this critical developmental period should be considered in children with significant torticollis (greater than $20^{\circ}$ ), which can be robustly measured and is consistent across several clinical visits [76].

\section{Clinical tips}

As part of the pre-operative assessment of horizontal AHPs, all patients should be observed for at least $5 \mathrm{~min}$ to be certain that one is not dealing with PAN. In addition, the authors would generally advocate more than one repeat orthoptic examination and careful history taking regards head posture direction. Where the possibility of PAN arises from either, EMRs should be considered for confirmation. PAN has been noted to be common in albinism.

In INS, the use of a dynamic target, such as a video, can elicit AHPs that may not be evident on testing of static VA.

In the authors experience, significant duction deficits are rarely seen using this surgical paradigm and avoiding a nonanchored hang-back technique in favour of either direct scleral suture or anchored hang-back techniques. 
Table 6 Simplified guide to AHP surgery in INS.

\begin{tabular}{|c|c|c|}
\hline Horizontal AHP & Abducting eye & Adducting eye \\
\hline \multicolumn{3}{|c|}{ A minimum dosage (in $\mathrm{mm}$ ) on each eye of $2 / 3$ the AHP (in degrees) is recommended [81] } \\
\hline Mild $24^{\circ}-30^{\circ}$ & $\operatorname{LRc}(-)$ and $\mathrm{MRs}(+) 8.0-10.0 \mathrm{~mm}$ & $\operatorname{MRc}(-)$ and $\operatorname{LRs}(+) 8.0-10.0 \mathrm{~mm}$ \\
\hline Moderate $30^{\circ}-36^{\circ}$ & $\operatorname{LRc}(-)$ and $\mathrm{MRs}(+) 10.0-12.0 \mathrm{~mm}$ & $\operatorname{MRc}(-)$ and $\operatorname{LRs}(+) 10.0-12.0 \mathrm{~mm}$ \\
\hline Severe $>36^{\circ}$ & $\operatorname{LRc}(-)$ and $\mathrm{MRs}(+) 12.0-14.0 \mathrm{~mm}$ & $\operatorname{MRc}(-)$ and $\operatorname{LRs}(+) 12.0-14.0 \mathrm{~mm}$ \\
\hline Graded Anderson & Lateral rectus recession & Medial rectus recession \\
\hline Minimal $15^{\circ}$ & $10.0 \mathrm{~mm}$ & $7.0 \mathrm{~mm}$ \\
\hline Mild $20^{\circ}-25^{\circ}$ & $11.0 \mathrm{~mm}$ & $8.0 \mathrm{~mm}$ \\
\hline Moderate $30^{\circ}$ & $12.0 \mathrm{~mm}$ & $9.0 \mathrm{~mm}$ \\
\hline $\begin{array}{l}\text { Moderate to severe } 35^{\circ} \\
\left(30^{\circ}-40^{\circ}\right)\end{array}$ & $10.0-17.0 \mathrm{~mm}$ & $13.0-15.0 \mathrm{~mm}$ \\
\hline \multicolumn{3}{|c|}{$\begin{array}{l}\text { In the presence of FMNS or a tropia, surgery should be performed on the fixing eye, with surgery for any } \\
\text { residual heterotropia performed on the non-fixing eye }[54,82]\end{array}$} \\
\hline Vertical AHP & Superior recti BE & Inferior recti $\mathrm{BE}$ \\
\hline \multicolumn{3}{|c|}{$\begin{array}{l}\text { A minimum dosage (in } \mathrm{mm} \text { ) on each eye of } \sim 1 / 4 \text { of the amount of head elevation/depression (in degrees) is } \\
\text { recommended [81] }\end{array}$} \\
\hline Chin-up $32^{\circ}-40^{\circ}$ & & $\operatorname{IRc}(-) 8.0-10.0 \mathrm{~mm}^{*}$ \\
\hline Chin-down $32^{\circ}-40^{\circ}$ & $\mathrm{SRc}(-) 8.0-10.0 \mathrm{~mm}$ & \\
\hline Chin-up $>40^{\circ}$ & & $\operatorname{IRc}(-) 10.0-12.0 \mathrm{~mm} *$ \\
\hline Chin-down $>40^{\circ}$ & $\operatorname{SRc}(-) 10.0-12.0 \mathrm{~mm}$ & \\
\hline \multicolumn{3}{|c|}{$\begin{array}{l}\text { Bilateral inferior rectus recessions may cause A-pattern deviation because of weakened adduction in down } \\
\text { gaze. The inferior rectus may be transposed nasally to avoid creating an A pattern }\end{array}$} \\
\hline Torsional AHP & Ipsilateral eye to tilt & Contralateral eye to tilt \\
\hline Torsion $15^{\circ}$ or less & $\begin{array}{l}\text { Induce excyclotorsion } \\
\text { Infraplacement of MR and } \\
\text { supraplacement of LR } 1 / 2 \mathrm{TW}\end{array}$ & $\begin{array}{l}\text { Induce incyclotorsion } \\
\text { Infraplacement of LR and } \\
\text { supraplacement of MR } 1 / 2 \mathrm{TW}\end{array}$ \\
\hline Torsion $15^{\circ}$ or greater & $\begin{array}{l}\text { Induce excyclotorsion } \\
\text { Infraplacement of MR and } \\
\text { supraplacement of LR } 1 \mathrm{TW}\end{array}$ & $\begin{array}{l}\text { Induce incyclotorsion } \\
\text { Infraplacement of LR and } \\
\text { supraplacement of MR } 1 \mathrm{TW}\end{array}$ \\
\hline PAN [83-85] & Right eye & Left eye \\
\hline & $\operatorname{LRc}(-)$ and $\operatorname{MRc}(-) 10.0-12.0 \mathrm{~mm}$ & $\operatorname{LRc}(-)$ and $\operatorname{MRc}(-) 10.0-12.0 \mathrm{~mm}$ \\
\hline
\end{tabular}

$\overline{M R c(-)}$ medial rectus recession, $L R c(-)$ lateral rectus recession, $M R s(+)$ medial rectus resection, $L R s(+)$ lateral rectus resection, $S R c(-)$ superior rectus recession, $I R c(-)$ inferior rectus recession, $B E$ both eyes, $T W$ tendon width

\section{Ongoing management}

Due to the often-complex medical needs of children with nystagmus, continued ophthalmic care is important; particularly for those with structural eye disorders, such as retinal dystrophies or anterior segment dysgenesis, who may need intraocular pressure checks or retinal therapies in addition to management of the nystagmus. Orthoptic follow-up of children with nystagmus is needed to provide timely identification and treatment of any associated amblyopia and management of strabismus. Coexisting strabismus and amblyopia should be treated conventionally, as appropriate for each individual, without specific changes to account for the nystagmus [77, 78]. Referral to paediatric low vision services is recommended at an early stage, so that low vision aids can be introduced with training to use them. Ongoing access to low vision and orthoptic services provides an opportunity to support children and parents as they face new challenges, such as starting nursery and full-time school, in both the provision of information and updated management options depending on the child's needs.

A particularly difficult time for parents and older children is at discharge from hospital eye services to the general optical service. Lack of information transferring with the child often leads, at least, to difficult consultations for optometrists, but more concerningly, to patients feeling that community-based eye-care practitioners do not understand their condition, losing their trust in the care received. In some instances, the lack of information transitioning with the patient leads to inappropriate re-referral and reinvestigation due to concerning 'new' findings that are long-standing but unknown to the referrer. Clear discharge information given to the patient is advised, including: a description of the nystagmus and any associated head posture, full diagnosis of the type of nystagmus and associated conditions, results of specific investigations carried out (e.g. genetic testing, EDTs, summary of 
treatments given, refractive correction and BCVA) and any certification completed (severely sight impaired/sight impaired). Patient and GP combined ownership of this discharge report with clear support mechanisms for the future are vital in allowing patients to have positive experiences in subsequent participation in society and future eye care.

\section{Patient support and resources}

\section{Information}

It is hard to exaggerate the value of information about nystagmus and associated condition(s) to patients and their families [79]. Generally, patients' questions fall into three categories: why do they or their child(ren) have nystagmus (cause), how will it affect them (impact) and what can be done about it (solution)?

Knowing the cause of the nystagmus (specific diagnosis) has many benefits for patients and clinicians alike. Even when no specific treatment is identified, an accurate diagnosis empowers families to talk about nystagmus, understand the context and what the future may hold and to advocate for themselves and/or their children. In addition, the wider family often wants to know the probability of others being born with nystagmus. Moreover, an accurate diagnosis will allow families to assess how future treatments may or may not benefit them, particularly as treatments are becoming more tailored to specific underlying aetiologies.

Parents especially want to understand the impact nystagmus has on their child. Their concerns typically include education, employment, driving and relationships (see Table 7). A realistic assessment of how nystagmus may affect each child is essential. Without it, parents will struggle to understand their needs and to make the necessary adaptations. Parents also have a vital role in explaining the impact of nystagmus to teachers and others involved in a child's education and development.

Over time, most patients accept that surgery and pharmaceuticals cannot cure nystagmus, although they may help in some cases. Nonetheless, it is important that patients fully understand the options available, including refraction and low vision aids, what will help, what will not help and why.

Clinicians may sometimes feel unable or lack the experience or time to answer some of these questions satisfactorily. It is important to recognise that national and local organisations exist to provide this support and reduce the strain on health services (see Table 8).

'Following the initial shock and panic, we did as most parents would do in this situation, and went against medical advice and consulted the internet for information. After scaring ourselves silly, we eventually came across the
Table 7 A single year of enquiries to the patient support charity, Nystagmus Network (NN), in 2015.

\begin{tabular}{ll}
\hline Enquiries (phone, email and social media) to Nystagmus & Number \\
Network helpline, 2015 & \\
\hline UK general public enquiries & 495 \\
Overseas enquiries & 127 \\
Enquiries from UK professionals & 271 \\
Administration, fundraising, volunteering & 293 \\
Total & 1186 \\
UK general public enquiries by category & Number \\
General support and information & 233 \\
Research and treatment & 70 \\
Education & 64 \\
Benefits and discrimination & 47 \\
Acquired nystagmus & 29 \\
Employment & 18 \\
Driving and transport & 18 \\
Other & 16 \\
Total & 495 \\
\hline
\end{tabular}

Source: data prepared for NN annual report 2015 and presented at NN Annual General Meeting, Birmingham, 7th May 2016

Table 8 Examples of national support groups.

\begin{tabular}{|c|c|c|}
\hline Name & Region & Website \\
\hline Albinism Fellowship & National & $\begin{array}{l}\text { http://www.albinism.org. } \\
\text { uk/ }\end{array}$ \\
\hline Aniridia Network & National & https://aniridia.org.uk/ \\
\hline $\begin{array}{l}\text { CVI Society (cerebral visual } \\
\text { impairment) }\end{array}$ & National & https://cvisociety.org.uk/ \\
\hline LOOK & National & http://www.look-uk.org/ \\
\hline Nystagmus Network & National & $\begin{array}{l}\text { https://nystagmusnetw } \\
\text { ork.org/ }\end{array}$ \\
\hline RNIB & National & https://www.rnib.org.uk/ \\
\hline VICTA & National & https://www.victa.org.uk/ \\
\hline
\end{tabular}

It is important to note that many local support groups are also an excellent source of information and support for children with nystagmus and their families

Nystagmus Network.... We have found their support and advice invaluable in helping us to accept and understand the diagnosis better'. (Comment to NN helpline published in NN's 2013 annual report).

\section{The role of Certificate of Vision Impairment (CVI) registration}

Based on anecdotal evidence to the authors over 30 years, issuing a child or an adult who has nystagmus with a CVI is in most cases a great help. Although the concrete benefits may appear limited, in practice, having a CVI enables 
patients to access support they may otherwise be denied. For instance, it is now difficult for a child with nystagmus to get an Education Health and Care Plan without first having a CVI.

A CVI also helps in accessing sports and entertainment venues, obtaining travel concessions and using the Department of Work and Pensions Access to Work scheme. Very few patients find CVIs a stigma. Patients can choose to revoke their CVI, for example if vision is good enough to apply for a driving licence at age 17 .

'Having been spurred on by your advice I mentioned the various difficulties to my optician the next time I went. She referred me to the local hospital where I saw an ophthalmologist who immediately said I should be registered visually impaired. The process was much easier than I imagined'. (Comment to NN helpline published in NN's 2014 annual report).

\section{Patient perspective}

Ideally, when patients are discharged from hospital they should have a realistic understanding of the impact nystagmus will have on them or their child. This should extend beyond VA and include the null zone, the difficulties caused by clutter/crowding and movement, the additional time needed to see (slow-to-see phenomenon), the variability of vision and whether or not the nystagmus is part of a progressive or largely static condition. Often simple things can have a great impact such as sitting children in class in a position in which they can utilise, rather than be penalised, by their null zone.

Patients should also be aware of the potential social impacts of nystagmus. For instance, research [80] suggests that the cosmetic consequences of nystagmus (abnormal head posture, flickering eyes and difficulty making eye contact) are underestimated and contribute to feelings of isolation, low self-esteem and depression.

The challenge for clinicians, at a time when we are still learning about the impacts of nystagmus and how to measure them, is knowing where to strike the correct balance. On the one hand, patients should not be discharged thinking 'nystagmus is the end of the world'. On the other hand, they should not leave a hospital eye department thinking nystagmus will have no impact at all.

\section{Summary}

Children with nystagmus are not uncommon in paediatric ophthalmic practice. Despite this, investigation and clinical management can vary widely across the UK and beyond. It seems likely that this is due to a potent combination of clinical concern regarding urgent underlying causes, subtlety to the clinical examination, variability of clinical picture and limited understanding of the mechanisms involved in causality. Herein, we hope to provide some information to clinicians on how children with nystagmus are currently managed in specialist centres in the UK and highlight the view of patients and their families. We hope that this will help us move towards improved health equity across UK centres for children with nystagmus and demystify what is often a relatively straight-forward, methodical approach.

Nystagmus UK Eye research group (NUKE) G. E. Arblaster ${ }^{10}$, A . Bjerre $^{10}$, M. J. Dunn ${ }^{3}$, J. T. Erichsen ${ }^{3}$, I . Gottlob ${ }^{4}$, H. J. Griffiths ${ }^{5}$, C. Harris $^{6}$, H. Lee ${ }^{1,2}$, L. McIlreavy ${ }^{3}$, J. Owen ${ }^{6}$, J. Sanders ${ }^{7}$, J. E. Self ${ }^{1,2}$, F. Shawkat $^{1}$, M. Theodorou ${ }^{8,9}$, J. P. Whittle ${ }^{10}$, D. Osborne ${ }^{1,2}$, M. Ranger $^{1,2}$, C. Norman ${ }^{2}$, K. MacKenzie ${ }^{8}$, N. Venturi ${ }^{8}$, TailorV ${ }^{8}$, Frank Proudlock $^{4}$, Rebecca McLean ${ }^{4}$, Mervyn Thomas ${ }^{4}$, Viral Sheth ${ }^{4}$, Perry Carter $^{1}$

\section{Compliance with ethical standards}

Conflict of interest The authors declare that they have no conflict of interest.

Publisher's note Springer Nature remains neutral with regard to jurisdictional claims in published maps and institutional affiliations.

Open Access This article is licensed under a Creative Commons Attribution 4.0 International License, which permits use, sharing, adaptation, distribution and reproduction in any medium or format, as long as you give appropriate credit to the original author(s) and the source, provide a link to the Creative Commons license, and indicate if changes were made. The images or other third party material in this article are included in the article's Creative Commons license, unless indicated otherwise in a credit line to the material. If material is not included in the article's Creative Commons license and your intended use is not permitted by statutory regulation or exceeds the permitted use, you will need to obtain permission directly from the copyright holder. To view a copy of this license, visit http://creativecommons. org/licenses/by/4.0/.

\section{References}

1. Sarvananthan N, Surendran M, Roberts EO, Jain S, Thomas S, Shah N, et al. The prevalence of nystagmus: the Leicestershire nystagmus survey. Investig Ophthalmol Vis Sci. 2009;50:5201-6.

2. Gottlob I, Zubcov A, Catalano RA, Reinecke RD, Koller HP, Calhoun JH, et al. Signs distinguishing spasmus nutans (with and without central nervous system lesions) from infantile nystagmus. Ophthalmology. 1990;97:1166-75.

3. Leigh RJ, Zee DS. The neurology of eye movements. New York: Oxford University Press; 2006.

4. Casteels I, Harris CM, Shawkat F, Taylor D. Nystagmus in infancy. Br J Ophthalmol. 1992;76:434-7.

5. Osborne D, Theodorou M, Lee H, Ranger M, Hedley-Lewis M, Shawkat F, et al. Supranuclear eye movements and nystagmus in children: a review of the literature and guide to clinical examination, interpretation of findings and age-appropriate norms. Eye. 2019;33:261-73. 
6. Brodsky MC, Fray KJ. The prevalence of strabismus in congenital nystagmus: the influence of anterior visual pathway disease. JAAPOS. 1997;1:16-9.

7. Dell'Osso LF. Congenital, latent and manifest latent nystagmussimilarities, differences and relation to strabismus. Jpn J Ophthalmol. 1985;29:351-68.

8. Abadi RV, Dickinson CM. Waveform characteristics in congenital nystagmus. Doc Ophthalmol. 1986;64:153-67.

9. Dell'Osso LF, Flynn JT, Daroff RB. Hereditary congenital nystagmus. An intrafamilial study. Arch Ophthalmol. 1974;92: 366-74.

10. Brodsky MC, Fray KJ. Positive angle kappa: a sign of albinism in patients with congenital nystagmus. Am J Ophthalmol. 2004;137:625-9.

11. Hove MN, Kilic-Biyik KZ, Trotter A, Grønskov K, Sander B, Larsen $\mathrm{M}$, et al. Clinical characteristics, mutation spectrum, and prevalence of Åland eye disease/incomplete congenital stationary night blindness in Denmark. Investig Ophthalmol Vis Sci. 2016;57:6861-9.

12. Benouaich X, Mahieu L, Matonti F, Soler V. Persistence of foveal capillary plexi in a case of fovea plana evident on OCT angiography. J Fr Ophtalmol. 2017;40:4-7.

13. Bowl W, Andrassi-Darida M, Holve K, Schweinfurth S, Knobloch R, Lorenz B. [Handheld optical coherence tomography in paediatric ophthalmology: experience of the Department of Ophthalmology in Giessen]. Klin Monbl Augenheilkd. 2016; 233:1142-8.

14. Sánchez-Vicente JL, Contreras-Díaz M, Llerena-Manzorro L, Rueda T, López-Herrero F, Molina-Socola FE, et al. Foveal hypoplasia: diagnosis using optical coherence tomography angiography. Retin Cases Brief Rep. 2018;12:122-6.

15. Langlo CS, Patterson EJ, Higgins BP, Summerfelt P, Razeen MM, Erker LR, et al. Residual foveal cone structure in CNGB3-associated achromatopsia. Investig Ophthalmol Vis Sci. 2016;57:3984-95.

16. Lee H, Proudlock FA, Gottlob I. Pediatric optical coherence tomography in clinical practice-recent progress. Investig Ophthalmol Vis Sci. 2016;57:69-79.

17. Kumar V, Molla K, Chandra P, Kumar A. Dome-shaped macula in oculocutaneous albinism. BMJ Case Rep. 2016;2016. https:// doi.org/10.1136/bcr-2016-215368.

18. Al Oreany AA, Al Hadlaq A, Schatz P. Congenital stationary night blindness with hypoplastic discs, negative electroretinogram and thinning of the inner nuclear layer. Graefes Arch Clin Exp Ophthalmol. 2016;254:1951-6.

19. Bouraoui R, Bouladi M, Nefaa F, Limaiem R, El Matri L. Role of $\mathrm{SD}-\mathrm{OCT}$ in the diagnosis and prognosis of macular hypoplasia in nystagmus patients. J Fr Ophtalmol. 2016;39:272-6.

20. Matalia J, Rajput VK, Chillal GJ, Shetty BK. Upbeat nystagmus in a 3.5-year-old boy. J Aapos. 2016;20:88-90.

21. Hull S, Arno G, Holder GE, Plagnol V, Gomez K, Liesner R, et al. The ophthalmic presentation of Hermansky-Pudlak syndrome 6 . Br J Ophthalmol. 2016;100:1521-4.

22. Mallipatna A, Vinekar A, Jayadev C, Dabir S, Sivakumar M, Krishnan N, et al. The use of handheld spectral domain optical coherence tomography in pediatric ophthalmology practice: our experience of 975 infants and children. Indian J Ophthalmol. 2015;63:586-93.

23. Mohammad S, Gottlob I, Sheth V, Pilat A, Lee H, Pollheimer E, et al. Characterization of Abnormal optic nerve head morphology in albinism using optical coherence tomography. Investig Ophthalmol Vis Sci. 2015;56:4611-8.

24. Han R, Wang X, Wang D, Wang L, Yuan Z, Ying M, et al. GPR143 gene mutations in five Chinese families with X-linked congenital nystagmus. Sci Rep. 2015;5:12031.

25. McCafferty BK, Wilk MA, McAllister JT, Stepien KE, Dubis $\mathrm{AM}$, Brilliant $\mathrm{MH}$, et al. Clinical insights into foveal morphology in albinism. J Pediatr Ophthalmol Strabismus. 2015;52:167-72.
26. Putnam CM, Bland PJ. Macular pigment optical density spatial distribution measured in a subject with oculocutaneous albinism. $\mathrm{J}$ Optom. 2014;7:241-5.

27. Cornish KS, Reddy AR, McBain VA. Concentric macular rings sign in patients with foveal hypoplasia. JAMA Ophthalmol. 2014;132:1084-8.

28. Cai CY, Zhu H, Shi W, Su L, Shi O, Cai CQ, et al. A novel splicing site mutation of the GPR143 gene in a Chinese X-linked ocular albinism pedigree. Genet Mol Res. 2013;12:5673-9.

29. Thomas S, Thomas MG, Andrews C, Chan WM, Proudlock FA, McLean RJ, et al. Autosomal-dominant nystagmus, foveal hypoplasia and presenile cataract associated with a novel PAX6 mutation. Eur J Hum Genet. 2014;22:344-9.

30. Lee H, Purohit R, Sheth V, McLean RJ, Kohl S, Leroy BP, et al. Retinal development in infants and young children with achromatopsia. Ophthalmology. 2015;122:2145-7.

31. Lee H, Sheth V, Bibi M, Maconachie G, Patel A, McLean RJ, et al. Potential of handheld optical coherence tomography to determine cause of infantile nystagmus in children by using foveal morphology. Ophthalmology. 2013;120:2714-24.

32. Lee H, Proudlock F, Gottlob I. Is handheld optical coherence tomography reliable in infants and young children with and without nystagmus? Investig Ophthalmol Vis Sci. 2013;54:8152-9.

33. Thomas MG, Kumar A, Mohammad S, Proudlock FA, Engle EC, Andrews C, et al. Structural grading of foveal hypoplasia using spectral-domain optical coherence tomography a predictor of visual acuity? Ophthalmology. 2011;118:1653-60.

34. Clark R, Blundell J, Dunn MJ, Erichsen JT, Giardini ME, Gottlob I, et al. The potential and value of objective eye tracking in the ophthalmology clinic. Eye. 2019;33:1200-2.

35. Dell'Osso L, Gauthier G, Liberman G, Stark L. Eye movement recordings as a diagnostic tool in a case of congenital nystagmus. Am J Optom Arch Am Acad Optom. 1972;49:3-13.

36. Ramat S, Leigh RJ, Zee DS, Shaikh AG, Optican LM. Applying saccade models to account for oscillations. Prog Brain Res. 2008;171:123-30.

37. Kriss A, Russell-Eggitt I. Electrophysiological assessment of visual pathway function in infants. Eye. 1992;6:145-53.

38. McCulloch DL, Marmor MF, Brigell MG, Hamilton R, Holder GE, Tzekov R, et al. Erratum to: ISCEV standard for full-field clinical electroretinography (2015 update). Doc Ophthalmol. 2015;131:81-3.

39. Shawkat FS, Kriss A, Thompson D, Russell-Eggitt I, Taylor D, Harris C. Vertical or asymmetric nystagmus need not imply neurological disease. Br J Ophthalmol. 2000;84:175-80.

40. O'Gorman L, Norman CS, Michaels L, Newall T, Crosby AH, Mattocks C, et al. A small gene sequencing panel realises a high diagnostic rate in patients with congenital nystagmus following basic phenotyping. Sci Rep. 2019;9:13229.

41. Thomas MG, Maconachie G, Sheth V, McLean RJ, Gottlob I. Development and clinical utility of a novel diagnostic nystagmus gene panel using targeted next-generation sequencing. Eur J Hum Genet. 2017;25:725-34.

42. Norman CS, O'Gorman L, Gibson J, Pengelly RJ, Baralle D, Ratnayaka JA, et al. Identification of a functionally significant triallelic genotype in the Tyrosinase gene (TYR) causing hypomorphic oculocutaneous albinism (OCA1B). Sci Rep. 2017;7: 4415.

43. Jayaramachandran P, Proudlock FA, Odedra N, Gottlob I, McLean RJ. A randomized controlled trial comparing soft contact lens and rigid gas-permeable lens wearing in infantile nystagmus. Ophthalmology. 2014;121:1827-36.

44. Theodorou M, Quartilho A, Xing W, Bunce C, Rubin G, Adams $\mathrm{G}$, et al. Soft contact lenses to optimize vision in adults with idiopathic infantile nystagmus: a pilot parallel randomized controlled trial. Strabismus. 2018;26:11-21. 
45. Mehta AR, Kennard C. The pharmacological treatment of acquired nystagmus. Pr Neurol. 2012;12:147-53.

46. Kalla R, Strupp M. Aminopyridines and acetyl-DL-leucine: new therapies in cerebellar disorders. Curr Neuropharmacol. 2019;17:7-13.

47. McLean RJ, Gottlob I. The pharmacological treatment of nystagmus: a review. Expert Opin Pharmacother. 2009;10:1805-16.

48. McLean R, Proudlock F, Thomas S, Degg C, Gottlob I. Congenital nystagmus: randomized, controlled, double-masked trial of memantine/gabapentin. Ann Neurol. 2007;61:130-8.

49. ANDERSON JR. Causes and treatment of congenital eccentric nystagmus. Br J Ophthalmol. 1953;37:267-81.

50. Goto N. A study opt nystagmus electro-oculogram. 1954;58:851-65.

51. Kestenbaum A. Novell operation du nystagmus. 1954;2:851-65.

52. Parks MM. Symposium: nystagmus. Congenital nystagmus surgery. Am Orthopt J. 1973;23:35-9.

53. Nelson LB, Ervin-Mulvey LD, Calhoun JH, Harley RD, Keisler MS. Surgical management for abnormal head position in nystagmus: the augmented modified Kestenbaum procedure. $\mathrm{Br} \mathrm{J}$ Ophthalmol. 1984;68:796-800.

54. Calhoun JH, Harley RD. Surgery for abnormal head position in congenital nystagmus. Trans Am Ophthalmol Soc. 1973;71:70-83. Discussion 4-7.

55. Kang NY, Isenberg SJ. Kestenbaum procedure with posterior fixation suture for anomalous head posture in infantile nystagmus. Graefes Arch Clin Exp Ophthalmol. 2009;247:981-7.

56. Lee IS, Lee JB, Kim HS, Lew H, Han SH. Modified Kestenbaum surgery for correction of abnormal head posture in infantile nystagmus: outcome in 63 patients with graded augmentaton. Binocul Vis Strabismus Q. 2000;15:53-8.

57. Taylor JN, Jesse K. Surgical management of congenital nystagmus. Aust N Z J Ophthalmol. 1987;15:25-34.

58. Scott WE, Kraft SP. Surgical treatment of compensatory head position in congenital nystagmus. J Pediatr Ophthalmol Strabismus. 1984;21:85-95.

59. Schild AM, Thoenes J, Fricke J, Neugebauer A. Kestenbaum procedure with combined muscle resection and tucking for nystagmus-related head turn. Graefes Arch Clin Exp Ophthalmol. 2013;251:2803-9.

60. Kommerell G. Surgical management of altered head posture in patients with congenital nystagmus (author's transl). Klinische Monatsblatter fur Augenheilkd. 1974;164:172-91.

61. Pratt-Johnson JA. Results of surgery to modify the null-zone position in congenital nystagmus. Can J Ophthalmol. 1991;26:219-23.

62. Sandall GS. Surgical treatment of congenital nystagmus in patients with singular binocular vision. Ann Ophthalmol. 1976;8: 227-38.

63. Kraft SP, O'Donoghue EP, Roarty JD. Improvement of compensatory head postures after strabismus surgery. Ophthalmology. 1992;99:1301-8.

64. Chang YH, Chang JH, Han SH, Lee JB. Outcome study of two standard and graduated augmented modified Kestenbaum surgery protocols for abnormal head postures in infantile nystagmus. Binocul Vis strabismus Q. 2007;22:235-41.

65. Biglan AW, Hiles DA, Ying-Fen Z, Kortvelesy JS, Pettapiece MC
66. Spielmann A. Clinical rationale for manifest congenital nystagmus surgery. J Aapos. 2000;4:67-74.

67. Kumar A, Shetty S, Vijayalakshmi P, Hertle RW. Improvement in visual acuity following surgery for correction of head posture in infantile nystagmus syndrome. J Pediatr Ophthalmol Strabismus. 2011;48:341-6.

68. ElKamshoushy A, Shawky D, ElMassry A, ElBaha S, Abdel Wahab MM, Sprunger D. Improved visual acuity and recognition time in nystagmus patients following four-muscle recession or Kestenbaum-Anderson procedures. J Aapos. 2012;16:36-40.

69. Biglan AW, Hiles DA, Ying-Fen Z, Kortvelesy JS, Pettapiece MC. Results after surgery for null point nystagmus with abnormal head position. Am Orthop J. 1989;39:134-42.

70. Lee J. Surgical management of nystagmus. J R Soc Med. 2002;95:238-41.

71. Kushner BJ. The usefulness of the cervical range of motion device in the ocular motility examination. Arch Ophthalmol. 2000;118:946-50.

72. Mitchell PR, Wheeler MB, Parks MM. Kestenbaum surgical procedure for torticollis secondary to congenital nystagmus. J Pediatr Ophthalmol Strabismus. 1987;24:87-93.

73. Tyedmers M, Roper-Hall G. The harms tangent screen test. Am Orthopt J. 2006;56:175-9.

74. Harms H. Ueber die Untersuchung der Augenmuskellahmungen. Graefes Arch Ophthalmol. 1941;144:129.

75. Pourahmadi MR, Bagheri R, Taghipour M, Takamjani IE, Sarrafzadeh J, Mohseni-Bandpei MA. A new iPhone application for measuring active craniocervical range of motion in patients with non-specific neck pain: a reliability and validity study. Spine J. 2018;18:447-57.

76. Dell'Osso LF, Flynn JT. Congenital nystagmus surgery. A quantitative evaluation of the effects. Arch Ophthalmol. 1979;97:462-9.

77. von Noorden GK, Avilla C, Sidikaro Y, LaRoche R. Latent nystagmus and strabismic amblyopia. Am J Ophthalmol. 1987;103:87-9.

78. Thurtell MJ, Leigh RJ. Therapy for nystagmus. J Neuroophthalmol. 2010;30:361-71.

79. Bjerre A, Arblaster GE, Nye A, Griffiths HJ. The provision of patient information about nystagmus. Br Ir Orthopt J. 2018;14:25-9.

80. McLean RJ, Windridge KC, Gottlob I. Living with nystagmus: a qualitative study. Br J Ophthalmol. 2012;96:981-6.

81. Gräf M, Droutsas K, Kaufmann H. Congenital nystagmus: indication, results and dosage of Kestenbaum surgery in 34 patients. Klinische Monatsblatter fur Augenheilkd. 2000;217:334-9.

82. Wang P, Lou L, Song L. Design and efficacy of surgery for horizontal idiopathic nystagmus with abnormal head posture and strabismus. J Huazhong Univ Sci Technol Med Sci. 2011;31:678-81.

83. von Noorden GK, Sprunger DT. Large rectus muscle recessions for the treatment of congenital nystagmus. Arch Ophthalmol. 1991;109:221-4.

84. Arruga A. Posterior fixation of recti in nystagmus with retinal detachment. Mod Probl Ophthalmol. 1975;15:304-6.

85. Mühlendyck H, Linnen HJ. The operative treatment of nystagmus-caused variable squint angles with Cüppers "Fadenoperation" (author's transl). Klinische Monatsblatter fur Augenheilkd. 1975;167:273-90.

\title{
Affiliations
}

\author{
J. E. Self $\mathbb{D}^{1,2} \cdot$ M. J. Dunn $\mathbb{D}^{3} \cdot$ J. T. Erichsen ${ }^{3} \cdot$ I. Gottlob ${ }^{4} \cdot$ H. J. Griffiths ${ }^{5} \cdot$ C. Harris ${ }^{6} \cdot$ H. Lee $\mathbb{D}^{1,2} \cdot$ J. Owen ${ }^{6}$.

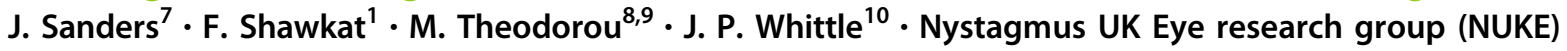


1 University Hospital Southampton, Southampton, UK

2 Clinical and Experimental Sciences, School of Medicine, University of Southampton, Southampton, UK

3 School of Optometry and Vision Sciences, Cardiff University, Cardiff, UK

4 Ulverscroft Eye Unit, Department of Neuroscience, Psychology and Behaviour, University of Leicester, Leicester, UK

5 Division of Ophthalmology and Orthoptics, Health Sciences School, University of Sheffield, Sheffield, UK
6 Royal Eye Infirmary, Derriford Hospital, Plymouth, UK

7 Patient Representative, Plymouth, UK

8 Paediatric Ophthalmology and Strabismus, Moorfields Eye Hospital, London, UK

9 National Institute for Health Research Biomedical Research Centre at Moorfields Eye Hospital, London, UK

10 Eye Department, Sheffield Children's Hospital, Sheffield, UK 